\title{
Miranda
}

Revue pluridisciplinaire du monde anglophone /

Multidisciplinary peer-reviewed journal on the English-

speaking world

$20 \mid 2020$

Staging American Nights

\section{Electronic music on show in museum context}

Review of the exhibition Electro, de Kraftwerk à Daft Punk, at the Philharmonie de Paris between 9 April and 11 August 2019

\section{Daniel Huber}

\section{OpenEdition}

Journals

\section{Electronic version}

URL: http://journals.openedition.org/miranda/26607

DOI: 10.4000/miranda.26607

ISSN: 2108-6559

Publisher

Université Toulouse - Jean Jaurès

\section{Electronic reference}

Daniel Huber, "Electronic music on show in museum context", Miranda [Online], 20 | 2020, Online since 20 April 2020, connection on 16 February 2021. URL: http://journals.openedition.org/miranda/26607 ; DOI: https://doi.org/10.4000/miranda.26607

This text was automatically generated on 16 February 2021.

\section{(c) $(7)$}

Miranda is licensed under a Creative Commons Attribution-NonCommercial-NoDerivatives 4.0 International License. 


\title{
Electronic music on show in museum context
}

\author{
Review of the exhibition Electro, de Kraftwerk à Daft Punk, at the
} Philharmonie de Paris between 9 April and 11 August 2019

\section{Daniel Huber}

1 Questions such as Is electronic music the sound of the future? or Does electronic music still have its liberating capacity? or Is electronic music capable of renewing itself? were pivotal for the whole exhibition, as explained by Marie-Pauline Martin, Director of the Music Museum in Paris and Laurent Bayle, General Director of the Cite de la MusiquePhilharmonie de Paris ${ }^{1}$, in their introduction to the exhibition. The answer to this set of questions was a rich, immersive experience that presented the history of electronic music, its inventors, its instruments, its major figures, as well as the contemporary dancefloor experience, and also its eternal future because what is our present was at some point in time their future aspiration. This review concentrates more closely on the contribution of the English-speaking world to the electronic music scene. ${ }^{2}$ The optimistic message of Electro, de Kraftwerk à Daft Punk is that electronic music culture is still very much engaged in its social and political intentions. House, techno and, more broadly, electronic music, are vehicles of gathering people, of all colours, genders, social backgrounds and walks of life, on dancefloors, on social media and through the activism of various collectives, which all help create an inclusive social network for our atomistic, individualistic society. This optimism and continued vitality of the electronic music scene echoes in the editorials of Les Inrockuptibles2 and the March and April 2019 issues of TRAX magazine that published special or thematic issues on occasion of the exhibition at the Philharmonie, Paris.

Jean-Yves Leloup, exhibition curator ${ }^{3}$ and chief editor of the accompanying catalogue, in his introduction (2019: 7), entitled "Codes and culture", claims that since 2010 electronic music has definitely positioned itself as a major artistic trend in contemporary culture. It is no longer restricted to rave parties and festivals, and it now has a long history. The exhibition draws a convincing direct line from the experimental electro-acoustic music of research studios to the emergence of house in Chicago and 
techno in Detroit in the early 1980s. What is nowadays referred to as electronic dance music (EDM), was born, in parallel with the digital revolution, in the underground clubs in Chicago and Detroit playing house and techno music. Due to the influence of its visionary Afro-American musicians and DJs, this music spread to Europe, from the late 1980 s on, in the form of secret rave parties where it found fertile ground for continued musical experimentation. The cultural importance of this musical trend is testified by the huge inspiration it has been for various artistic expressions presented in the exhibition $^{4}$ : plastic artwork by Xavier Veilhan, Carsten Nicolai, Christian Marclay, Bruno Peinado, Sculpture, installations by 1024 Architecture, photography by Andreas Gursky, Jacob Khrist, Alfred Steffen, Hervé Lassïnce, George Nebieridze ${ }^{5}$, Julie Hascoët, Sasha Mademuaselle and video art by Jan Kounen, Joe Wilson, Chris Cunningham ${ }^{6}$, Kevin McGloughlin, graphic art by Alan Oldham, Peter Saville, Anthony Burrill, Abdul Qadim Haqq, So Me, and Ludovic Houplain. Artistic gestures such as mixing, remixing, sampling and the aesthetics of the vinyl record as object and of live stage performance have become commonplace and widely applied to many other domains such as cinema (article by Thierry Jousse, 2019: 80-85), graphic novels (Alan Oldham) as well as performance arts and dance choreography ${ }^{7}$ (Gisèle Vienne ${ }^{8}$ and Alexandre Roccoli ${ }^{9}$ ). Queer activism, DIY and artisanal solutions, nomadistic festivalgoers reveal the political and counter-cultural appeal of electronic music. ${ }^{10}$

3 The subtitle of the exhibition deserves some attention, especially when compared to the titles of the special and thematic issues of Inrockuptibles2 and Trax. The exhibition subtitle made clear reference to Kraftwerk and Daft Punk, two emblematic European groups very much in activity on the contemporary electro scene, but the exhibition went far beyond the timespan and geographical range of From Kraftwerk to Daft Punk. The subtitle does not quite bring out the depth and richness of the material presented. Nevertheless, a crucial aspect of their influence was highlighted in Jean-Yves Leloup's article in the catalogue (2019: 38-41): Kraftwerk ${ }^{11}$ remains to this day the German and European musical influence on the Afro-American music scene, from producers of disco to the electro-funk wave between 1982-1984, to resident DJs in New York City throughout the 1980s, to figures of Detroit techno such as Derrick May ${ }^{12}$, Juan Atkins ${ }^{13}$, Kevin Saunderson ${ }^{14}$ or Jeff Mills ${ }^{15}$ as well as the hip-hop scene between 1980 and 2010. Since Kraftwerk and Daft Punk were actively involved in the production of the scenography, Kraftwerk ${ }^{16}$ providing a custom 3D installation in a room of its own and Daft Punk ${ }^{17}$ a special installation of Technologic Redux in a space of its own, the subtitle is best accepted as reflecting aspects of a private and public joint production of such an exhibition in a museum. The Inrockuptibles2 special issue had as subtitle From the origins to our day, which is indeed a more apt solution. Noémie Lecoq's editorial pointed out that electro music is an affair with multiple intricate ramifications, artistic cross-influences and dancefloor experience, and insisted that electro music is very Human After All ${ }^{18}$. Trax magazine came out with two thematic issues, in March on Detroit and in April on They put rave in the museum!, which thus address specific aspects of the exhibition. Lucien Rieul, deputy editor-in-chief of Trax magazine in his enthusiastic editorial to the April 2019 issue, "Aesthetic Shock", summarizes a relevant point of view of the (electronic) music community on the museum presentation of (electronic) music. In his view, while "one vinyl record on the wall is one disc fewer that's playing on a turntable", it's also true that "sometimes a disc must stop playing so one can have a better look at the work of a talented illustrator on its label". Indeed, 
pausing for a moment to consider the rich cross-fertilization between electro music and other ways of artistic expression remains one of the major achievements of Electro.

On entering the exhibition space, visitors were immediately immersed in the scenography of Electro, imagined by Pier Schneider and François Wunschel, the duo behind 1024 Architecture studio ${ }^{19}$. The exhibition space, painted black, aimed at replicating the experience of live electro raves, with surrounding music, with the scaffolding as the main architectural feature and neon lights. On either wall hang two monumental chromogenic prints by Andreas Gursky, of the Düsseldorf school of photography, showing party scenes with crowds "raving" on the dancefloor. This visual effect strengthened the message of the immersive scenography to visitors. Farther in the exhibition space, to the left, there was a more museal run of low showcases above which hang a timeline frieze cuing the typography and colour scheme prevalent throughout the exhibition and the catalogue: contour letters in neon colours of turquoise and blue against a black backdrop. Another key feature of the interactive scenography of the exhibition was when visitors received a pair of earphones to listen to videos and documentary footage, a piece of electronic music or to the sound produced by these, sometimes curious, inventions. Along the middle of this first "room", there were various showcases formed of scaffolding tubes that housed an imitation home studio. The soundtrack that could be heard in the whole exhibition was mixed by Laurent Garnier especially for Electro: a mix composed of 126 titles, arranged into 11 categories, each around 30 minutes long, such as The Disco Era Mix, The Chicago Jacking Zone, Detroit Mix, New York City Mix, The Second Summer of Love Mix, French Mix, and Futuristic Techno, that played on loop during opening hours (the complete tracklist is available in the catalogue (2019: 170-171), and three sets are available on YouTube ${ }^{20}$ ). A richly illustrated catalogue in French, published jointly by Textuel and Philharmonie de Paris, accompanied the show, although translations in English and German would have been coherent with the scenography and the concept of the exhibition. Visitors to the exhibition did have access to English texts in the exhibition space.

The exhibition space had five sections, each presenting electronic music from a specific point of view. Man \& Woman Machine focused on the relation between humans and machines, presented from more of an external point of view of music history. Dancefloor presented the immersive electronic music scene as experienced by the public. Mix \& Remix talked about the experience of DJs behind the turntables in the studios, in the clubs, and about what is going on on stage. Imaginaires (Imaginaries) further developed the analysis of the visual representation of electronic music and the underlying myths, while Utopies (Utopias) was concerned with some of the social and political aspirations of various currents in electronic music.

\section{Man \& Woman Machine}

6 Man and Woman Machine ${ }^{21}$ focused on the historical development of electronic music and the key inventions and figures in this history. It covered topics as diverse as the invention of various musical instruments, the emergence of computer generated or computer assisted music, the visual aspect of electronic music as represented by the artwork on album covers from the 1950s to the 1980s, and the graphic artwork on the 
round labels on the discs, and the live audio-visual experience of stage performance. It also contained the material of Detroit techno in particular.

7 A long display presented the arch of the history of electronic music that extends from the invention of various musical instruments in the early $20^{\text {th }}$ century, through experimental and creative work in research studios of the post-war period, to the pioneer producers of techno and house in Detroit and Chicago in the early 1980s, and the contemporary lively musical scene. This history is imbued with a faith in the progress of science, the possibility to construct a whole new world on the ruins of World War II, the imaginary world of sci-fi as well as an utopian idea of humans and machines living in harmony, which would lead to an expansion of our consciousness and our capabilities. This display presented many of these revolutionary or visionary instruments, synthesisers, samplers, beatboxes and others: Don Buchla and his Buchla 200 Series synthesiser, 1970-1978 (2019: 18), Robert Moog and his Moog55 synthesiser, 1975 (2019: 19), and Daphne Oram's The Oramics Machine, 1957 (2019: 26), or the TB-303 bass synthesizer developed by Roland in 1982. Moritz Simon Geist's MR-808 Robotic Drum Machine (2013) was available for visitors to experiment with "live". ${ }^{22}$

Between 1948 and 1968, electronic music was essentially an avant-garde practice. It was closely related to the exploration and experimentation of composers and engineers in research studios. These studios were financed in different ways. Some received funding from public television and radio companies as in the case of the BBC Radiophonic Workshop in London, where Daphne Oram was active in the late $1950 \mathrm{~s}^{23}$, or the Studio für elektronische Music at the WDR studios in Cologne $e^{24}$. Others were housed in universities such as Columbia University in New York with Milton Babbitt ${ }^{25}$. Yet others were housed in private technology companies such as the NatLab at Philips in Eindhoven, in the Netherlands ${ }^{26}$, or Siemens' electronic music studio in Gauting, Germany ${ }^{27}$. While these studios mostly had what can be seen today as very rudimentary equipment (microphones, loudspeakers, oscillators and ring modulators), the tape recording technology made editing possible, with feedback, loop, echo and delay effects. Many composers and musicians tried to create a new kind of music and musical tradition, dispensing with traditional classical music and the concert form. ${ }^{28}$ To this end, they often invented instruments or new ways of composing and producing music.

9 It was in this context of the 1960s that Jean-Yves Leloup interviewed the composer and engineer Peter Zinovieff for the catalogue (2019: 32-33). Zinovieff talked about the role and legacy of Electronic Music Studios (EMS), the company he co-founded in London in 1969 and that invented and commercialized the VCS3 synthesizer ${ }^{29}$ in the same year (2019: 44). He explained how, in the 1960s, concrete music, that is recording natural sound, and electronic music, that generating primitive electronic sounds, were the only two aesthetics, and both relied on the use of tape-recording as the means of editing and fixing music. While Zinovieff, as a composer, was influenced by contemporary composers such as Pierre Boulez and the Groupe de recherches musicales in Paris, who considered electronic music as the music of the future, the instruments invented by EMS had a huge influence on contemporary pop musicians, such as Paul McCartney and Ringo, who were regulars at the open days of the studio. Another aspect in which Zinovieff was a precursor of contemporary electronic music was the numerous concerts they gave, in particular the series annual concerts for five or six years at the Queen Elisabeth Hall in London in the late 1960s. The effervescence of the period was 
instrumental in the technological changes and the creativity that electronic music embodied.

10 A special showcase along the middle line of this first "room" in the exhibition space displayed six instruments such as Jean-Michel Jarre's first VCS3 synthesizer (1969), a Small Stone pedal (1974) and a Geiss Matrisequencer (1978), from his private collection: they formed an imaginary home studio, with partitions scattered on the floor, books on the shelves, stands and loudspeakers. ${ }^{30}$ The back of these cases was decorated with 62 album covers of the pioneers and the avant-garde of electronic music, selected by Samon Takahashi from his own collection. Covers for Prospective $21^{e}$ siècle ${ }^{31}$ published by Philips between 1967 and 1978 are very clear in their futuristic and maybe utopian ideals. Covers for electro-acoustic or concrete music from the 1960s to the 1980s show a visual taste for abstract and geometrical design ${ }^{32}$ such as Pythagoron (1977) ${ }^{33}$ or Interpenetrations (1984), electronic music by Denis Smalley ${ }^{34}$, Jonty Harrison, and Tim Souster of the University of East Anglia. Various covers for albums of a psychedelic trend at the turn of the 1960s and 70s and album covers from the 1970s show artwork that matches a more meditative, cosmic or even New Age musical aesthetics.

11 The section on the techno scene Detroit in the late 1980s was composed of photographs and video excerpts, and presented the emergence of techno music. The selection of black and white close-up portraits by German photographer Marie Staggat ${ }^{35}$ of the key figures at the origin of Detroit techno were taken between 2013 and 2015 and included Kevin Saunderson, Kenny Larkin ${ }^{36}$, Blake Baxter. The portraits, taken decades after the beginning of their career, are a crucial reminder that this music has its roots in the Afro-American communities in the industrial context of Detroit. Techno music has striven to construct its imaginary on the ruins of the past splendour of the city, since the automobile and social crisis at the end of the 1980s. Musicians and DJs such as Juan Atkins $^{37}$, Derrick May, Jeff Mills ${ }^{38}$, Mike Banks ${ }^{39}$, Robert Hood, and visual artists such as Haqq or Alan Oldham created a world that took its inspiration from science-fiction and technological innovation to create a musical and visual universe with futuristic tonalities, percussive rhythms filled with energy, and dreamlike accords and melodious landscapes. The colour photographs from American photographer Christopher Woodcock's 2005 series, Bedroom Rockers, invited visitors to the personal world and home studios, frequently the living room, of musicians and DJs of the American underground electronic music scene. The photos showed rooms filled with electronic studio equipment, vinyl records stacked high on bookshelves and album covers scattered around both on tables and the floor, posters on the wall, with references to Kraftwerk for instance: images of creative effervescence taken as if in the middle of a typical workday. ${ }^{40}$ The documentary video ${ }^{41}$ on Jitting Jesus from the Urban Dance Legends series was a useful biographical note to the theme of the Detroit urban music scene.

12 Another series of Detroit photographs were Jarod Lew's Maybe I'll See You There (2015 ongoing). In this series, Jarod Lew, a 32-years old photographer and Detroit native, looks at the relationship between Detroit's population and their urban environment in the middle of the uncertain transformation of Detroit. It is interesting to compare the selection in the March issue of Trax (pp. 48-55) and in the exhibition catalogue because while the exhibition carried 6 photos, the Trax article has 7 and only 2 overlap between them. The Trax selection, unlike the catalogue, also includes short explanatory texts to present the context of each photo, and an introduction by Jarod Lew: "With this series, 
I've tried to explore the impact of change, by trying to understand the uncertainty of the future for each of us in a town that's looking for its new identity".

The illustrations on the labels of Underground Resistance albums of the 1990s are iconographically very interesting. The label, founded by Mike Banks (Mad Mike) ${ }^{42}$, Jeff Mills and Robert Hood in 1989 in Detroit, called for change by sound revolution and made references to comic books ${ }^{43}$, the African diaspora, space travel ${ }^{44}$ and interstellar communication, urban spaces ${ }^{45}$, slogans ${ }^{46}$ and propaganda rhetorics. The graphic creative behind the label illustrations was Frankie Fultz. It is curious that the catalogue editors did not choose to include the discographic elements for these albums, unlike for the album covers above. I have compiled this list in (1):

Underground Resistance titles

UR-009 (1991) Elimination ${ }^{47}$ UR-010 (1991) Riot EP ${ }^{48}$

UR-017 (1991) Punisher ${ }^{49}$

UR-018 (1992) Fury ${ }^{50}$

UR-022 (1992) Death Star ${ }^{51}$

UR-029 (1994) Dark Energy ${ }^{52}$

UR-030 (1994) Drexciya Aquatic Invasion ${ }^{53}$

UR-033 (1995) Electronic Warfare ${ }^{54}$

UR-054 (2004) Perception - Abandoned Building In Mono ${ }^{55}$

UR-069 (2005) Interstellar Fugitives 2 - The Destruction Of Order ${ }^{56}$

UR-071 (2007) Hi-Tech Dreams/Lo-Tech Reality ${ }^{57}$

The selection of material on display for the figure of the robot consisted of various video clips that showed machines at work such as in a factory context, presented in a pure, metallic, colour-scheme ${ }^{58}$, sometimes emotionally interacting with humans as in Björk's All is Full of Love (1999) ${ }^{59}$ or rebelling against being exploited by the human world $^{60}$. Johanna Vaude's 2015 video editing Robots et cinéma took video samples from a vast range of films ${ }^{61}$, from Terminator to Japanese anime, and the original electro soundtrack was interspersed with film citations on loop. The various video clips of live $\mathrm{A} / \mathrm{V}$ stage performance revealed an aspiration to some form of immersive total art to techno pop music. ${ }^{62} \mathrm{~A}$ telling example was the custom 3D video installation THE CATALOGUE 12345678 (2017) ${ }^{63}$ by Kraftwerk. This installation, together with Walking Cube $^{64}$ (2014-2015) and Core (2019) by 1024 Architecture were the ideal transition within the exhibition space to the Dancefloor section.

\section{Dancefloor}

This section took the perspective of partygoers dancing all together on the dance floor where they all take a plunge in the same light effects and music. It presented two different ways of consuming music: in New York City, presented as dancefloor city with its legendary (and sometimes scandalous) clubs, before going over to the Second Summer of Love in England and its rave culture. This section had the highest proportion of photographs in the exhibition. Furthermore, the relationship between dancefloor and use of drugs was presented. 

can mingle in a spirit of communion and freedom that is not necessarily available outside the club, the spacious warehouse, the abandoned factory building or some secret building lost in the countryside. The exhibition space actually opens with two giant, $164 \times 275 \mathrm{~cm}$ and 205x505cm, C-prints from Andreas Gursky's Union Rave (1995) and Mayday (2000) series. Arms stretched and raised high all at the same time or elbows bent at $45^{\circ}$ holding a glass of drink (or not) show crowds of people whose apparent chaos is pulled into harmony by the rhythm of the music they are listening to. Several installations by 1024 Architecture studio evoked the moving light effects and the prevailing rhythm of the clubs, such as Walking Cube (2014-2015) and Core (2019).

New York is considered to be the city that invented the modern club and the culture around them. The art of mixing and the aesthetics of electronic music club culture developed in the early 1970s in gay clubs such as The Loft, Better Days or The Gallery: DJs mixing and remixing vinyl records, released on the new 12" maxi singles, pumping 4-beat rhythms, matching the immersive sound effects and scenography of these clubs. Studio 54 eventually stood out on the club scene of late 70s New York, though. In a 2014 Vogue Homme interview (Sabas 2014), Ian Schrager, co-founder with Steve Rubell of Studio 54, talks about the melting-pot this nightclub represented of the glitter chic and extravagance of late 1970s New York, during its short, explosive, well-documented existence between April 1977 and February 1980. Schrager explains that Studio 54 was more about all the enormous social changes that were happening at the time such as the widespread acceptance of the contraceptive pill, a general sense of freedom across Western Europe and North America, the emergence of the gay civil rights movement. It was more about mixing people, rather than about disco music itself, although Freak by Chic (1978) was on the airwaves of the period and White Lines (1983) by Melle Mel and Grandmaster Flash was in the air. Paul Flynn in his review of the book on Studio 54 by Ian Schrager (published by Rizzoli in 2017) explains (2017: 248):

...Studio 54 has become the subject of every art director's glamour mood board. When boys who read nu-disco blogs hear the opening strains of Love Hangover, Relight My Fire or Was That All It Was, it is their imaginary Studio 54 valve that those propulsive basslines first tickle. When a stylist slips into a kaftan, it is to the back stairwell of Studio their sartorial choice transports them. [...] When you want to designate a particular brand of louche elegance on a night-time scene, Studio 54 is the natural first port of comparative call.

He also points out that Obama, who had declared Frankie Knuckles Day in Chicago in 2004, added Ian Schrager, on leaving office as President, to a list of professional pardons, for the tax evasion conviction that saw Schrager and Rubell, owners of Studio 54, incarcerated for a year, the conviction that put an end to the existence of the club.

During the 1980s, New York does not stop dancing, to the sound of disco and garage, which takes its name from the Paradise Garage club. Disco and garage gave way to New York house, an import from Chicago arriving in New York in the early 1990s, this energetic melodious and vocal party music that has influenced modern dance music in a decisive fashion. Photographers Bill Bernstein (late 1970s) and Tina Paul (1980-1990) immortalized much of the New York City clubbing scene in this period. Bernstein's shots give a glimpse at the mythical disco clubs The Fun House or The Paradise Garage and Le Clique, an atmosphere where people of different ethnic and social origins could mingle to the rhythm of New York disco music. Tina Paul's photos document the period 
where a new generation of DJs, such as Larry Levan, David Morales and Frankie Knuckles $^{65}$, made New York the home of house and garage music (named after The Paradise Garage club) from the mid-1980s to the early 1990s, in the gigantic clubs such as Sound Factory or MARRS. Bill Bernstein in his interview to the catalogue (2019: 9899) talks about this period in New York, the rise and fall of disco music. He recalls how disco music was intimately associated in its origin with the gay community and the clubs that emerged, and how the ominous Disco Demolition event in July 1979, with clear racist and homophobic overtones, meant in a way the end of disco. He also points out that this fervent music scene corresponded to a particular social situation where New York, economically in ruins after the crisis of the early 1970s, was home to poor, marginal people and artists that made this creative and political effervescence possible.

The Second Summer of Love of 1987-88 in England was directly related to the arrival of Chicago house music ${ }^{66}$. A decade after punk, this new revolution turned social codes upside down again: the concept of clubbing became democratized and party culture came to be seen as a liberating reaction to the economic crisis and Thatcher's authoritarianism. The period is also marked by the more massive use of acid and by spreading the culture of rave parties organized illegally on abandoned industrial sites or in the countryside around London and major towns such as Manchester. Pop culture, fashion, design, contemporary art including photography still take inspiration in the aesthetics and memories of this effervescent movement that created a link between industrial sites and places of physical work and the strict industrial rhythms of acid house and techno. Peter Walsh photographed the acid house and rave scene in 1989 in Manchester at the Haçienda and Boardwalk clubs and during the Joy Rave, organized in the neighbouring countryside. Peter Saville's Halluçienda posters, commissioned by the Haçienda club in Manchester in 1989, as well as his album cover for the Fine Time ${ }^{67}$ (1988) single by New Order, released on Factory Records, accompanied fittingly the photographs of the North of England scene. His images are inspired by pop art, mechanical reproduction, with references to art history as well as testifying of the intimate relationship between electronic music and various acid substances. The Haçienda club is also noteworthy for its French connexion: a certain Laurent Garnier, who provided the soundtrack of the exhibition, also mixed there during this period. ${ }^{68}$

The vast selection of photographs of rave culture across the world included Massimo Vitali in Italy, Alfred Steffen ${ }^{69}$ during the Love Parade in Berlin in 1996, Agnès Dahan's Soirées Respect, Queen, in Paris between 1997-1999, Sasha Mademuaselle's Skotoboinya series in Moscow in 2015, Jacob Khrist's photos from 2017-2018, Vincent Rosenblatt's Rio Baile Funk series 2009. The American photographer Roger Kisby took portraits of candy ravers, participants of the Electric Daisy Carnival, an itinerant EDM festival, in 2014-2016: the name candy raver refers to the colourful outfits, bracelets and headgear participants are fond of. Completing this section about the various dancefloor scenes around the world, the video clip Ice Drop (2017) by the South African DJ Lag ${ }^{70}$, showing alternative dance floors such as rooftops was remarkable.

\section{Mix \& Remix}

This section focused on the role of the DJ, techniques of mixing and sampling, the figure of DJ Frankie Knuckles, and the aesthetics of the vinyl album as their working tool and as the ideal visual object related to this music world. It revolved around key 
concepts such as mixing, sampling, citation, appropriation, and how these techniques resonated with visual and performance artists then and since. According to the DJs interviewed for the catalogue by Patrick Thévenin (2019: 152-155), the art of beat and frequency matching for aesthetically appealing transitions between tracks, an immense musical culture and constant search for inspiring pieces, and an ability to adapt to the atmosphere of the club or party to give fuel to the dancefloor, are the ingredients for providing a strong-impact live experience for the public, for making them dance and find their way to themselves, through "making music with music" in Jeff Mill's words.

Patrick Thévenin's article for the catalogue on Frankie Knuckles ${ }^{71}$ and the history of Chicago house (2019: 156-159) completed the history of electronic music in North America. In the early 1970s the emergence, in New York City, of disco and its more hedonistic approach to dance music corresponded to the gay and Afro-American civil rights movements and sexual emancipation. Knuckles, who was born in the Bronx, learnt the art of Djing in various clubs such as The Loft in New York before moving to Chicago to be the resident DJ and thus the DJ of the opening night of the Warehouse in 1977. The Warehouse was an afterhours club, not serving alcohol at all, but the dancefloor transpired both under the music, the light show and the influence of acid and MDA. After the Disco Demolition Night in 1979, Knuckles started mixing in electronic beats to his disco sets and editing from tapes his favourite passages to assemble them in a new way, in order to keep the tradition alive...by pushing it eventually in another direction by 1984 . House was born at the Warehouse, and was ready to be transported to Europe, especially to England, for the Second Summer of Love.

The techniques of sampling, remixing and citation resemble the technique of the collage, and found natural analogies with the visual art material in the section. For his series Body Mix (1991-1992), Christian Marclay assembled various album covers of the period to form a collage of David Bowie for instance, his method imitating sampling. His Recycled Records (1984) series consisted of vinyl records made of mixed-up visual elements, album cover photographs, drawings, comic strips, all referencing pop culture extensively. Sculpture's The Zoetropic Gallery (nd) ${ }^{72}$ also revolves around the shape and aesthetics of the circle of the vinyl record: concentric patterns of photographs, each layer is a narrative as if they were consecutive film stills, showing for instance a pill, as it dissolves in water. Samon Takahashi's A Rainbow in Curved Air from his series Plundersymphony (2006) is a photograph of hundreds of vinyl albums as if on a shelf, the colour of the spines of the albums forming waves of colours rainbows.

\section{Imaginaires (Imaginaries)}

This section was also rich in various visual artwork related to the culture of electronic music: album cover art, video clip artwork and live audio-visual performances draw heavily on the aesthetics of abstract geometry, robotics and technologies of the future, and a Romantic idea of landscapes devoid of any human presence. This part of the exhibition went deeper into the graphic design aspect of album covers that the selection in the main, adjacent exhibition space, had already introduced. The interest in abstract, geometrical, Op Art designs on psychedelic albums from the 1960s made their way into computer-generated designs in the video artwork for music videos ${ }^{73}$ and as integral part of live performances ${ }^{74}$. The sci-fi aesthetics of the technology of the 
future, spaceships, foreign planets ${ }^{75}$, astronaut's helmet, and the fusion between machines and humans make for interesting narratives in electronic music videos ${ }^{76}$. English graphic artist Anthony Burrill's series of flyers for the Balearica nights of The Social in London also use geometrical patterns, as does his music video for Acid Washed $^{77}$ (2009). This graphic universe corresponds the often instrumental genres of electronic music, without sung vocals. ${ }^{78}$ It is also in relationship, especially in the hands of Afro-American graphic artists, with Afro-futurism, a set of ideas revisiting questions of slavery and diaspora, the fight for equal rights, as filtered through a world of science fiction. While the absence of lyrics often corresponds to the impossibility or refusal of expressing ideas in words or the unreliability of inter-human communication.

Images and video artwork in reference to landscapes are very relevant to a conceptualization of the contemporary human condition. For instance, repetitive designs such as interwoven webs of overpasses and motorways, lifts going up and down in a robotic manner ${ }^{79}$, glass surfaces everywhere, the total absence of the individual yet an omnipresence of human intervention make for a somewhat eerie, mechanic, planned, centrally controlled, futuristic yet not unknown visual environment. Other strands of visual representation provided images and video artwork cuing elements of industrial infrastructure such as trains, or geological features used as the basis of increasing abstract motifs in the designs (waveforms of electronic pulses drawing rivers and mountains or images of mountains decomposing into waveform to the rhythm of the electronic music ${ }^{80}$. This universe answers to the repetitive, mechanical, machine-generated soundscape of electronic music. Neural synapses, electric explosions, webs of organic-looking tubes and arteries, and the trajectories of rockets, flying towards a fantasy world maybe, correspond visually to a utopian universe, of fertile irruptions and insemination, to the possibility of (re)birth, of a new beginning. ${ }^{81}$ The more than 120 albums whose cover was on display are listed in the catalogue (2019: 252).

Questions of anonymity were revealed by the cult(ure) of the mask as disguise. Producers of electronic music often cultivate an anonymous, disinterested stance with respect to questions of ego but visitors were also reminded of a vital instinct of underground music genres such as house and techno at their beginning. As pointed out by Benoit Hické in his article on Detroit techno in Inrockuptibles2 (p.28), members of the Detroit music label Underground Resistance consistently appeared on stage wearing a mask. This was partly in defiance to the economic crisis of the automobile industry and the ensuing unemployment, but also in defiance to the music industry that had a bad track record of financially exploiting young musicians and thus derailing the original spirit of techno. ${ }^{82}$ This intended anonymity is coupled to the perfectly autonomous methods of music production, in their own studios and their own distributions structure.

In "On Rave Art" (L'art de la rave, Trax, April 2019, pp. 42-47), Lucien Rieul asked four artists whose work is presented in the exhibition about how they think a live, intimate, collective, sometimes mystic and ever vibrant experience that is rave can be shown in an exhibition. These short testimonials are especially interesting in the case of Abdul Qadim Haqq, painter and illustrator for the label Underground Resistance from Detroit, and Carsten Nicolai, whose work were on show at the exhibition and credited duly in the catalogue but there was no more information about them either at the exhibition or in the catalogue. It was Abdul Qadim Haqq who gave the characteristic Afro-futuristic 
visual identity to techno music, by drawing comics- and sci-fi-inspired superheroes who navigate in space or in the underwater world, spaces representing the unknown but spaces that are also places of emancipation and freedom. His character Jaguar $\mathrm{Knight}^{83}$, for the cover of the eponymous mix by DJ Rolando, aka The Aztec Mystic (Underground Resistance, 1999), provides the face for the mystic-spiritual atmosphere of this solitary traveller of the tracks on the record. Another of his characters, Analogue Assassin ${ }^{84}$, evokes a different archetypal hero, that of rapid action, swift gestures, in tune with the pieces on the eponymous album (Underground Resistance, 2002). Abdul Qadim Haqq has striven to represent visually coherent imaginary civilisations, entire cultures and the stories that emerge from them, as is first evident in his artwork for Neptune's Lair ${ }^{85}$ by Drexciya (1999). Carsten Nicolai ${ }^{86}$, co-founder of the Raster-Noton label and producer under the pseudonym Alva $\mathrm{Noto}^{87}$, finds inspiration for his installations in the intersection of sound and the physics of propagating waves. In his series Chroma Wellenform (2015), shown in the exhibition, he represents sound without their temporal aspect but in the aesthetics of their waveform. The artist duo 1024 architecture studio, Pier Schneider and François Wunschel, discuss the difficulties in delivering a museum experience that involves sound, the visual and the spatial. They recall how in the late 1990s, when DJs started to do live sets on stage, their stage presence behind their decks needed something that was also visually engaging for the audience: digital art came in handy for that purpose. The architect duo uses light and digital artwork as construction material for their scenography. ${ }^{88}$ They also talk about the role of scaffolding in their installations: it references temporary constructions, very characteristic of festivals too. Their creative method includes analysing the music of the artist they are working with using algorithms to simulate the scenic behaviour of the music: "It is the music that makes our machines move", they say. They were in charge of both the overall scenography of the Electro exhibition and specific installations within the exhibition such as Walking Cube and, especially, Core, which makes reference both to the core of a computer used to generate, sample and mix electronic music, and the central place of the installation within the exhibition space. Finally, Alexandre Roccoli ${ }^{89}$, dancer and choreographer, who has worked with Chloé, Jeff Mills or Deena Abdelwahed ${ }^{90}$, explains that it was after a trip to Sri Lanka to learn about certain ritual mask dances with a curative effect that his attention turned to techno music and after-parties. In his view, the repetitive nature of the gestures of dance, through inducing modified states of body and mind, has a power of transformation: dancing for an extended period of time is thus capable of shredding layers of a personality and layers of our memories. His choreography also revolves around ideas about how a movement can become sonorous even in the absence of music, how people can actually hear sweating, breathing in and breathing out, the cardiac rhythms of our inner music.

\section{Utopies (Utopias)}

This section was closely related to Imaginaries, and the difference may well have passed unnoticed for many visitors. This is especially in that some key aspects, such as Afrofuturism, have been addressed in both sections even in the catalogue, and the representation or the use of landscape in the visual artwork was frequently full of political comment and activist engagement. Probably the main difference consisted in Utopias focusing more on what's yet to do and what are the current societal issues 
concerning racism, sexual discrimination for instance. It is all too easy to see that the questions themselves are intimately connected to artistic ways of rendering them. The club as the materialization of the desire for safer ${ }^{91}$ places for the LGBTQI+ community is related to altered representations of what the human body can look like: in machinehuman interactions or in futuristic representation of "alien creatures" or DJs simply being masked behind their turntables. Ideals of nomadism and communal living are also very much related to the underground, counter-cultural ethos of electronic music, and a number of photographic series attested to these practices.

41 A word must be said about women's presence in the exhibition. It was a very conscious (and very welcome) effort on the part of the curators and organizers to make women's presence visible in the world of electronic music and, more importantly, to make it an integral part of the exhibition concept from the outset rather than treating it separately. The introduction to the thematic sections both in the exhibition space and in the accompanying catalogue carried the same set of five photographs: three sections had a woman figure or portrait (Daphne Oram) to illustrate the theme, one a man and one...a robot. The same sensitivity to women's contribution was also felt in the material assembled: besides individual artists ${ }^{92}$, there was an extract from Mark Collin's feature film Le choc du future ${ }^{93}$ ("Future Shock", 2019) and a generous sample from the Visibility blog on Tumblr created in collaboration with composer-musician-poet AGF ${ }^{94}$ and Female Pressure ${ }^{95}$. Jean-Yves Leloup's article for the catalogue (2019: 230-234) presents an overview of major issues of representation on stage in festival programmes and women's place in the industry in general, history of electronic music taking stock of women's role as composers, musicians, sound designers, sound engineers and DJs, the scandal of misogyny and sexism in certain sections of the industry.

In this connection, the Trax article "Algorave. Code dancefloor" (pp.54-59) is particularly relevant here. The article concentrates on "algorave", which emerged from "live coding" of music on stage: algorave, first branded as such as 2012, involves mixing "live" a sort of progressive techno music while projecting psychedelic motifs and computer code, the code generating, in full transparency and full disclosure, the actual music the audience is listening to. The article presents the history and main figures of live coding and the algorave world and the main creative (and technical) challenges it has faced. What is of particular interest here with respect to Electro though, is the fact that this vibrant music scene emerged in Sheffield that had already had strong links to the alternative music scene in the North of England, and even more importantly, algorave is a decidedly inclusive segment of the music scene. This tallies with the thread picked up and developed in the exhibition, namely that electronic music has a track record of being more sensitive than other musical genres to the representation and stage presence of women artists and creatives as well as being more attentive to actively listen to women's ideas. Coral Manton, researcher (originator of the Women Reclaiming AI movement ${ }^{96}$ ) and creative coder, is regularly in demand to construct the visual aspect of a particular algorave, while Lucy Cheesman (aka Heavy Lifting ${ }^{97}$ ) is frequently on stage mixing live. The community is inclusive also in the sense that they organise workshops to teach the use of dedicated software. This ethics of do it yourself and free sharing does carry political messages: it is a scene where cyber feminism is a keyword and where showing one's computer screen to an entire concert hall is a thrilling act of transparency. Other political messages include their position to infuse 
humanity in the algorithms our machines use, thereby getting back human control over machines.

On another note of utopian ideas, the interview with Pierre Deruisseau in the catalogue (2019: 218-219) gives an analysis, from a psychological point of view, of the relation between music and mythologies in Afro-American communities ${ }^{98}$. Afro-futurism revolves around central visual elements such as the figure of the robot or the cyborg and the spaceship. They are found as stage costumes, in dances and songs, and on album covers. He points out that these elements refer, partly, to the slave ships ${ }^{99}$, the robotic, machine-like gestures on the plantations, but also to questions of what home means in diaspora culture where home should be understood as a place "where they can stand up" (Sidney Bechet, cited by Deruisseau). The club can thus become that place where one can understand their identity and stand up for it.

The club is a crucial space also for the LGBTQI+ community for which clubs have historically represented safer places, a space of security, solidarity, emancipation, pride and which is relatively safer from ambient discrimination. Since the emergence of the club scene in New York in the early 1970s, disco music, house, techno have been the soundtrack of the civil rights movements, and clubs like The Loft provided the creative and energizing backdrop. Patrick Thévenin's article in the catalogue (2019: 212-216) gives an ideal outline of the impact of the music scene on contemporary gay and other LGBTQI+ cultures. He draws attention to the fact that disco, house and techno have all emerged, in consecutive waves, in clubs whose resident DJ was frequently openly gay. These influences found their way to England and Europe during the Second Summer of Love, and the international popularity of both house and techno, renamed or remixed into "acid house" in England, was unstoppable. This is when heterosexualization of these genres took place for mainstream and white music consumers in the early 2000s. Initiatives to re-politicize these safer places is summarized in the motto of our days: "We dance together, we fight together".

\section{Conclusion}

The exhibition Electro, de Kraftwerk à Daft Punk has convincingly demonstrated that electronic music has kept its potential to remain the sound of the future, of ideals and utopias. The complex networks of influence that the exhibition revealed, between European experimental electro-acoustic music of the post-war decades, its influence on German electronic music and their joint influence on North American communities where it cross-fertilized with Afro-American musical traditions only to come back to England and the wide world, has kept its full potential to be relevant for contemporary society. After having spread across the world and having become mainstream partly, electronic music still has its liberating capacity because it renews, and reconnects to, its underground roots in newer and newer communities around the world. This reconnection is all the more possible that electronic music is affirming its position as an inclusive and hedonistic culture where machines are used to make us feel more at ease with... our humanity after all.

Exhibition catalogue Electro, de Kraftwerk à Daft Punk, Jean-Yves Leloup (ed.) 2019, Éditions Textuel and the Cité de la musique-Philharmonie de Paris, $45 €$.

ISBN: 978-2-84597-765-5 


\section{BIBLIOGRAPHY}

Bardot, Patrice, Alexis Bernier. 2019. « Le grand débat. Où est passé le rêve électronique ? » In Tsugi 120 (March 2019), pp.20-29.

Brun-Lambert, David. 2019. « House Sweet House. » In Les Inrockuptibles 2 Electro.

Flynn, Paul. 2017. « The Boss. » In GQ Style 25 (Autumn/Winter 2017), pp.246-255.

Hické, Benoît. 2019. « Fleur de bitume. » In Les Inrockuptibles 2 Electro.

Leloup, Jean-Yves (ed.). 2019. Electro, de Kraftwerk à Daft Punk. Éditions Textuel and the Cité de la musique-Philharmonie de Paris, Paris.

Lecoq, Noémie (editor in chief). 2019. Les Inrockuptibles 2 Electro. Special issue.

Rieul, Lucien (deputy editor-in-chief). 2019. Trax.

Sabas, Carole. 2014. « Dancing King. » In Vogue Homme 20 (Autumn/Winter 2014-2015), pp. 158160.

\section{NOTES}

1. https://philharmoniedeparis.fr/fr/musee-de-la-musique

2. I have compiled a Youtube playlist that includes much of the audio material at the exhibition (and more, of course). The links in this review all point to an item on that list: https://www.youtube.com/playlist?list=PLgbI3v55sXFVw6DakIBv-b_SVFDhyRTHx

3. https://www.youtube.com/watch?v=mc6qYHTwG5o\&list=PLgbI3v55sXFVw6DakIBvb_SVFDhyRTHx\&index $=3 \& \mathrm{t}=0 \mathrm{~s}$

4. In this respect the present exhibition goes beyond the 2012 exhibition at the Musée des Arts Décoratifs in Paris, which focused on the visual aspect of the French Touch in electronic music: https://madparis.fr/francais/musees/musee-des-arts-decoratifs/expositions/expositionsterminees/french-touch-graphisme-video/

5. https://www.youtube.com/watch?v=LtDxZGbDJc8\&list=PLgbI3v55sXFVw6DakIBvb_SVFDhyRTHx\&index $=11$

6. https://www.youtube.com/watch?v=TZ827lkktYs\&list=PLgbI3v55sXFVw6DakIBvb_SVFDhyRTHx\&index $=139$

7. https://www.youtube.com/watch?v=3sai3TZypP4\&list=PLgbI3v55sXFVw6DakIBvb_SVFDhyRTHx\&index $=20$

8. https://www.youtube.com/watch?v=tbN5_CbfwNU\&list=PLgbI3v55sXFVw6DakIBvb_SVFDhyRTHx\&index $=16$

9. https://www.youtube.com/watch?v=M20QKcGDdME\&list=PLgbI3v55sXFVw6DakIBvb_SVFDhyRTHx\&index $=20 \& \mathrm{t}=0 \mathrm{~s}$

10. The April 2019 issue of Trax proves to be a relevant source of additional material on the exhibition, complementary to the catalogue. The magazine takes over the entire chapter by Thierry Jousse, entitled "Cinématech" (pp. 60-65), from the exhibition catalogue on a selection of the six films where the electronic music soundtrack plays a major role, exemplifying the multifarious interactions between this music and other art forms. Also, there are other texts and interviews that complement the Electro catalogue texts.

11. https://www.youtube.com/watch?v=hyC_0x8wruA\&list=PLgbI3v55sXFVw6DakIBvb_SVFDhyRTHx\&index $=21$ 
12. https://www.youtube.com/watch?v=I7HiL2m63pQ\&list=PLgbI3v55sXFVw6DakIBvb_SVFDhyRTHx\&index $=84$ and https://www.youtube.com/watch? v=rFQZndywOR4\&list=PLgbI3v55sXFVw6DakIBv-b_SVFDhyRTHx\&index=83
13. Performing
as
Cybotron:
https://www.youtube.com/watch?

v=1ZRQ6KqQ9aM\&list=PLgbI3v55sXFVw6DakIBv-b_SVFDhyRTHx\&index=82

14. https://www.youtube.com/watch?v=F1Q7_mdZN48\&list=PLgbI3v55sXFVw6DakIBvb_SVFDhyRTHx\&index $=84$

15. https://www.youtube.com/watch?v=ayzCnm_czZ4\&list=PLgbI3v55sXFVw6DakIBvb_SVFDhyRTHx\&index $=80$

16. https://www.youtube.com/watch?v=L4hGaV5BA2M\&list=PLgbI3v55sXFVw6DakIBvb_SVFDhyRTHx\&index $=104$

17. https://www.youtube.com/watch?v=fnWypQz6X2U\&list=PLgbI3v55sXFVw6DakIBvb_SVFDhyRTHx\&index $=23$

18. https://www.youtube.com/watch? $\mathrm{v}=$ PXYeARRyDWk\&list=PLgbI3v55sXFVw6DakIBvb_SVFDhyRTHx\&index $=37$

19. https://www.youtube.com/watch?v=A4BrfPXTwzA\&list=PLgbI3v55sXFVw6DakIBvb_SVFDhyRTHx\&index $=5 \& \mathrm{t}=0 \mathrm{~s}$

20. The Detroit Mix: https://www.youtube.com/watch? v=tQbT_hxAD6Y\&list=PLgbI3v55sXFVw6DakIBv-b_SVFDhyRTHx\&index=7 ; the French Mix: https://www.youtube.com/watch?v=3h2TxMmM7-o\&list=PLgbI3v55sXFVw6DakIBv-

b_SVFDhyRTHx\&index $=6$; the Second Summer of Love Mix: https://www.youtube.com/watch? v=sUIjHKFqQT4\&list=PLgbI3v55sXFVw6DakIBv-b_SVFDhyRTHx\&index $=5$

21. Referring to Kraftwerk's The Man-Machine (1978): https://www.youtube.com/watch? v=zHIsGqJaXXw\&list=PLgbI3v55sXFVw6DakIBv-b_SVFDhyRTHx\&index=21

22. https://www.youtube.com/watch?v=FFxJztQUGjw\&list=PLgbI3v55sXFVw6DakIBvb_SVFDhyRTHx\&index $=45$

23. https://www.youtube.com/watch?v=g1S8pDiuzJ4\&list=PLgbI3v55sXFVw6DakIBvb_SVFDhyRTHx\&index $=25$

24. https://www.youtube.com/watch?v=kBP1v29cx60\&list=PLgbI3v55sXFVw6DakIBvb_SVFDhyRTHx\&index=37 (in German but including much music by Stockhausen)

25. https://www.youtube.com/watch?v=W5n1pZn4izI\&list=PLgbI3v55sXFVw6DakIBvb_SVFDhyRTHx\&index $=29$

26. https://www.youtube.com/watch?v=IN6Vzdcoejc\&list=PLgbI3v55sXFVw6DakIBvb_SVFDhyRTHx\&index=24 (in Dutch)

27. https://www.youtube.com/watch?v=YYgAdnHWCtg\&list=PLgbI3v55sXFVw6DakIBvb_SVFDhyRTHx\&index $=36$

28. Examples included the following albums of the international scene: https:// www.youtube.com/watch?v=1QdDUFBHRJ4\&list=PLgbI3v55sXFVw6DakIBv-

b_SVFDhyRTHx\&index $=31$,

https://www.youtube.com/watch? v=B1erjW00yZM\&list=PLgbI3v55sXFVw6DakIBv-b_SVFDhyRTHx\&index=33, https:// www.youtube.com/watch?v=f9JrbwWL9VM\&list=PLgbI3v55sXFVw6DakIBvb_SVFDhyRTHx\&index $=36$

29. The instrument is presented by Jean-Michel Jarre as his very first synth, (2019: 44), while another synthesizer by EMS is illustrated (2019:27) in the catalogue.

30. https://www.youtube.com/watch?v=H3fOPVcKFt0\&list=PLgbI3v55sXFVw6DakIBvb_SVFDhyRTHx\&index $=3$

31. https://www.youtube.com/watch?v=BL5jjNYe2Dw\&list=PLgbI3v55sXFVw6DakIBvb_SVFDhyRTHx\&index $=30$

32. https://www.youtube.com/watch?v=h2nP0px7lUk\&list=PLgbI3v55sXFVw6DakIBvb_SVFDhyRTHx\&index $=29$ 
33. https://www.youtube.com/watch?v=HxJ7SRsSZf4\&list=PLgbI3v55sXFVw6DakIBvb_SVFDhyRTHx\&index $=26$

34. https://www.youtube.com/watch?v=ODhnCVJ22i8\&list=PLgbI3v55sXFVw6DakIBvb_SVFDhyRTHx\&index $=28$

35. https://www.youtube.com/watch?v=szTW3o4umdE\&list=PLgbI3v55sXFVw6DakIBvb_SVFDhyRTHx\&index=8

36. https://www.youtube.com/watch?v=Z5E8iBEq_hw\&list=PLgbI3v55sXFVw6DakIBvb_SVFDhyRTHx\&index $=48$

37. https://www.youtube.com/watch?v=zyVedSNxOaY\&list=PLgbI3v55sXFVw6DakIBvb_SVFDhyRTHx\&index=39

38. https://www.youtube.com/watch?v=eU-UsvYbIV0\&list=PLgbI3v55sXFVw6DakIBvb_SVFDhyRTHx\&index $=43$

39. https://www.youtube.com/watch?v=aPlRBcYC45Q\&list=PLgbI3v55sXFVw6DakIBvb_SVFDhyRTHx\&index=1

40. Qool DJ Marv, one of the musicians in Woodcock's series, can be seen at work in his home studio in this video :

https://www.youtube.com/watch?v=08TENAeZ1J8\&list=PLgbI3v55sXFVw6DakIBv-

b_SVFDhyRTHx\&index $=42$

41. https://www.youtube.com/watch?v=JB4vFOwUCHY\&list=PLgbI3v55sXFVw6DakIBvb_SVFDhyRTHx\&index $=85$

42. https://www.youtube.com/watch?v=2uIH859SVdM\&list=PLgbI3v55sXFVw6DakIBvb_SVFDhyRTHx\&index $=67$

43. https://www.youtube.com/watch?v=oJrHon509so\&list=PLgbI3v55sXFVw6DakIBvb_SVFDhyRTHx\&index $=60$

44. https://www.youtube.com/watch?v=03iD5HgIlmI\&list=PLgbI3v55sXFVw6DakIBvb_SVFDhyRTHx\&index $=66$

45. https://www.youtube.com/watch?v=aPlRBcYC45Q\&list=PLgbI3v55sXFVw6DakIBvb_SVFDhyRTHx\&index $=1$

46. https://www.youtube.com/watch?v=auQt2fjIzT0\&list=PLgbI3v55sXFVw6DakIBvb_SVFDhyRTHx\&index $=61$

47. https://www.youtube.com/watch?v=y3YXxWUOCPI\&list=PLgbI3v55sXFVw6DakIBvb_SVFDhyRTHx\&index $=76$

48. https://www.youtube.com/watch?v=FE4sppAIPWg\&list=PLgbI3v55sXFVw6DakIBvb_SVFDhyRTHx\&index $=66$

49. https://www.youtube.com/watch?v=Uclq1z0ey_s\&list=PLgbI3v55sXFVw6DakIBvb_SVFDhyRTHx\&index $=67$

50. https://www.youtube.com/watch?v=LeEHWefju_0\&list=PLgbI3v55sXFVw6DakIBvb_SVFDhyRTHx\&index $=70$

51. https://www.youtube.com/watch? $v=L c o X f m R 6 C v Q \& l i s t=P L g b I 3 v 55 s X F V w 6 D a k I B v-$ b_SVFDhyRTHx\&index=75

52. https://www.youtube.com/watch?v=5h6N10MGqqg\&list=PLgbI3v55sXFVw6DakIBvb_SVFDhyRTHx\&index=73

53. https://www.youtube.com/watch?v=2M1S_4fW_JE\&list=PLgbI3v55sXFVw6DakIBvb_SVFDhyRTHx\&index $=84$

54. https://www.youtube.com/watch?v=6h76n98R9QE\&list=PLgbI3v55sXFVw6DakIBvb_SVFDhyRTHx\&index $=81$

55. https://www.youtube.com/watch?v=TH0BEeYyMeM\&list=PLgbI3v55sXFVw6DakIBvb_SVFDhyRTHx\&index $=70$

56. https://www.youtube.com/watch?v=K6QxTNL5V0I\&list=PLgbI3v55sXFVw6DakIBvb_SVFDhyRTHx\&index $=78$ 
57. https://www.youtube.com/watch?v=_Jh79YfGDpw\&list=PLgbI3v55sXFVw6DakIBvb_SVFDhyRTHx\&index=71

58. https://www.youtube.com/watch?v=ie_2AwzoIH4\&list=PLgbI3v55sXFVw6DakIBvb_SVFDhyRTHx\&index $=125$

59. https://www.youtube.com/watch?v=u0cS1FaKPWY\&list=PLgbI3v55sXFVw6DakIBvb_SVFDhyRTHx\&index $=108$

60. https://www.youtube.com/watch?v=ETDEuH3YL7I\&list=PLgbI3v55sXFVw6DakIBvb_SVFDhyRTHx\&index $=126$

61. https://www.youtube.com/watch?v=-cc24ps757I\&list=PLgbI3v55sXFVw6DakIBvb_SVFDhyRTHx\&index $=107$

62. https://www.youtube.com/watch?v=ZaaFIYdX5Sg\&list=PLgbI3v55sXFVw6DakIBvb_SVFDhyRTHx\&index $=149$

63. https://www.youtube.com/watch?v=L4hGaV5BA2M\&list=PLgbI3v55sXFVw6DakIBvb_SVFDhyRTHx\&index $=96$

64. https://www.youtube.com/watch?v=w6VwiInwmEw\&list=PLgbI3v55sXFVw6DakIBvb_SVFDhyRTHx\&index $=13$

65. https://www.youtube.com/watch?v=WH5C1Fh53I0\&list=PLgbI3v55sXFVw6DakIBvb_SVFDhyRTHx\&index $=53$

66. https://www.youtube.com/watch?v=BDnl5PMY6gg\&list=PLgbI3v55sXFVw6DakIBvb_SVFDhyRTHx\&index $=46$

67. https://www.youtube.com/watch?v=JPLqmYhCBsQ\&list=PLgbI3v55sXFVw6DakIBvb_SVFDhyRTHx\&index $=101$

68. The articles in Les Inrockuptible2 Electro (pp.50-63) were devoted to Sheffield and Bristol, thus usefully completing the description of the various currents in England at the time.

69. https://www.youtube.com/watch?v=WplJdaMpJ5s\&list=PLgbI3v55sXFVw6DakIBvb_SVFDhyRTHx\&index $=9$

70. https://www.youtube.com/watch?v=9ycr4BI8I94\&list=PLgbI3v55sXFVw6DakIBvb_SVFDhyRTHx\&index $=86$

71. https://www.youtube.com/watch?v=_kWVv03Us78\&list=PLgbI3v55sXFVw6DakIBvb_SVFDhyRTHx\&index $=50$

72. https://www.youtube.com/watch?v=hWUt3Y0LwpI\&list=PLgbI3v55sXFVw6DakIBvb_SVFDhyRTHx\&index $=87$

73. https://www.youtube.com/watch?v=pnhM1N8CwwQ\&list=PLgbI3v55sXFVw6DakIBvb_SVFDhyRTHx\&index $=106$

74. https://www.youtube.com/watch?v=Zjs24FUrprg\&list=PLgbI3v55sXFVw6DakIBvb_SVFDhyRTHx\&index $=147$

75. https://www.youtube.com/watch?v=h6xlK1tmKpE\&list=PLgbI3v55sXFVw6DakIBvb_SVFDhyRTHx\&index $=108$

76. https://www.youtube.com/watch?v=ETDEuH3YL7I\&list=PLgbI3v55sXFVw6DakIBvb_SVFDhyRTHx\&index $=111$

77. https://www.youtube.com/watch?v=zAhFzB2JDDA\&list=PLgbI3v55sXFVw6DakIBvb_SVFDhyRTHx\&index $=111$

78. As far as the use of human language in electronic music is concerned, it is either completely absent or when present to some degree, it often becomes distorted in voice quality (see Kraftwerk's Autobahn, 1974) or repetitive as in ad campaign slogans (see Kraftwerk's Tour de France, 2003) or in political propaganda (see Kraftwerk's Radioactivity, 1975).

79. https://www.youtube.com/watch?v=n09aot9RgQc\&list=PLgbI3v55sXFVw6DakIBvb_SVFDhyRTHx\&index $=104$

80. https://www.youtube.com/watch?v=w-Q4qzeuV-8\&list=PLgbI3v55sXFVw6DakIBvb_SVFDhyRTHx\&index $=102$ 
81.

https://www.youtube.com/watch?v=mS5XJcmMMWc\&list=PLgbI3v55sXFVw6DakIBv-

b_SVFDhyRTHx\&index $=101$

82. The exploitative policy to the detriment of up and coming musicians is discussed by David Brun-Lambert in his article House Sweet House.

83. https://www.youtube.com/watch?v=C6xVKcvze74\&list=PLgbI3v55sXFVw6DakIBvb_SVFDhyRTHx\&index $=56 \& t=0$ s

84. https://www.youtube.com/watch?v=JM5yzrE9taQ\&list=PLgbI3v55sXFVw6DakIBvb_SVFDhyRTHx\&index $=54$

85. https://www.youtube.com/watch?v=gD274hf6X0Q\&list=PLgbI3v55sXFVw6DakIBvb_SVFDhyRTHx\&index $=90$

86. https://www.youtube.com/watch?v=5iABNDvZ8IA\&list=PLgbI3v55sXFVw6DakIBvb_SVFDhyRTHx\&index $=100$

87. https://www.youtube.com/watch?v=RaAsxo9u8tA\&list=PLgbI3v55sXFVw6DakIBvb_SVFDhyRTHx\&index=99

88. https://www.youtube.com/watch?v=S3CdAgqoGBU\&list=PLgbI3v55sXFVw6DakIBvb_SVFDhyRTHx\&index $=134$

89. https://www.youtube.com/watch?v=M20QKcGDdME\&list=PLgbI3v55sXFVw6DakIBvb_SVFDhyRTHx\&index $=19$

90. https://www.youtube.com/watch?v=pjPguTaZ_Yg\&list=PLgbI3v55sXFVw6DakIBvb_SVFDhyRTHx\&index $=121$

91. The term safer, rather than safe expresses the idea that there can be no safe spaces, they can at best be safer than other public spaces.

92. https://www.youtube.com/watch?v=KIV7WgSncKY\&list=PLgbI3v55sXFVw6DakIBvb_SVFDhyRTHx\&index=103, https://www.youtube.com/watch? v=qj6lUC6K4VQ\&list=PLgbI3v55sXFVw6DakIBv-b_SVFDhyRTHx\&index=104, https:// www.youtube.com/watch?v=g1MC21aCB_o\&list=PLgbI3v55sXFVw6DakIBv-

b_SVFDhyRTHx\&index=106, https://www.youtube.com/watch? v=OgN3_KXv508\&list=PLgbI3v55sXFVw6DakIBv-b_SVFDhyRTHx\&index=105, https:// www.youtube.com/watch?v=4vTRZPLyKX0\&list=PLgbI3v55sXFVw6DakIBvb_SVFDhyRTHx\&index $=103$

93. https://www.youtube.com/watch?v=aMcV3IZMbvo\&list=PLgbI3v55sXFVw6DakIBvb_SVFDhyRTHx\&index $=101$

94. https://www.youtube.com/watch?v=ZzumI_-2A9I\&list=PLgbI3v55sXFVw6DakIBv-

b_SVFDhyRTHx\&index $=135$

95. http://www.femalepressure.net/

96. https://womenreclaimingai.com/

97. https://www.youtube.com/watch?v=ca3J1cztnrc\&list=PLgbI3v55sXFVw6DakIBvb_SVFDhyRTHx\&index $=122$

98. https://www.youtube.com/watch?v=WqVq_QMH46E\&list=PLgbI3v55sXFVw6DakIBvb_SVFDhyRTHx\&index $=154$

99. https://www.youtube.com/watch?v=2M1S_4fW_JE\&list=PLgbI3v55sXFVw6DakIBvb_SVFDhyRTHx\&index $=75$ 
INDEX

Keywords: electronic music, vinyl record cover artwork, photography, installation, video, scenography, (re)mix, sampling, loop, house, techno, Chicago, Detroit, Manchester

Subjects: Music

Mots-clés: musique électronique, art de la pochette vinyle, photographie, installation, vidéo, scénographie, (re)mix, sampling, boucle, house, techno, Chicago, Detroit, Manchester

\section{AUTHORS}

\section{DANIEL HUBER}

Maître de conférences

Université de Toulouse 2 Jean Jaurès

daniel.huber@univ-tlse2.fr 